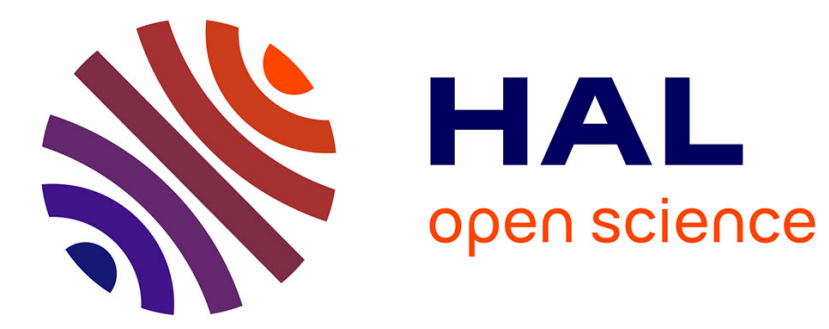

\title{
Molecular Dynamics Analysis of an Energetic System under Thermal and Shock Sollicitations
}

\author{
L. Soulard
}

\section{To cite this version:}

L. Soulard. Molecular Dynamics Analysis of an Energetic System under Thermal and Shock Sollicitations. Journal de Physique IV Proceedings, 1995, 05 (C4), pp.C4-599-C4-607. 10.1051/jp4:1995449 . jpa-00253755

\section{HAL Id: jpa-00253755 https://hal.science/jpa-00253755}

Submitted on 1 Jan 1995

HAL is a multi-disciplinary open access archive for the deposit and dissemination of scientific research documents, whether they are published or not. The documents may come from teaching and research institutions in France or abroad, or from public or private research centers.
L'archive ouverte pluridisciplinaire HAL, est destinée au dépôt et à la diffusion de documents scientifiques de niveau recherche, publiés ou non, émanant des établissements d'enseignement et de recherche français ou étrangers, des laboratoires publics ou privés. 
Molecular Dynamics Analysis of an Energetic System under Thermal and Shock Sollicitations

L. Soulard

CEV-M, BP. 7, 77181 Courtry, France

We present in this paper molecular dynamics calculations concerning the decomposition of a simple system $\mathrm{A}_{2} \rightarrow 2 \mathrm{~A}$ under thermal and shock sollicitations. For thermal decomposition, numerical results are consistent with the molecular collision theory. Arrhenius parameters are calculated. For shock decomposition, several regimes of propagation are observed depending upon the initial shock intensity. Analysis of chemical decomposition shows that kinetic parameters are strongly different from thermal decomposition.

\section{I - INTRODUCTION.}

The chemical process of decomposition in a reactive shock wave is far from being understood. Because both time and space scales of this phenomenon are very small, experiments must be performed at molecular level with a very high spatial and time resolution. Experiments are then extremely difficult to perform and interpret. Actually, molecular dynamics is the only one technique to provide information on atomic motions in a very small region during a very short time and some promising results are already published (ref. $/ 1 /-/ 6 /$ for example). In this paper we present first results using molecular dynamics obtained in our laboratory concerning energetic material in homogeneous phase.

The aim of this work is a numerical analysis by molecular dynamics of decomposition of a simple system : $\mathrm{A}_{2} \rightarrow 2 \mathrm{~A}$ under static (thermal) and dynamic conditions (shock). In the first part, we describe the potential function of the system. In the second part, thermal decomposition is analysed for several initial temperatures. Results are interpreted with the classical molecular collision theory. In part III, decomposition under shock is studied for three shock intensities. As in the second part, kinetic parameters are estimated. Finally, results of thermal and shock decompositions are compared. 


\section{II - POTENTIAL FUNCTIONS.}

By hypothesis, the potential function depends only upon interatomic distance $\mathrm{r}_{\mathrm{ij}}$ between atomes $i$ and $j$. It is consist of two empirical functions $\varepsilon_{1}$ and $\varepsilon_{2}$. The $\varepsilon_{1}$ function is a predissociative potential and describes interaction of atomes in a $\mathrm{A}_{2}$ molecule, that is $r_{i j}<r_{d}$, where $r_{d}$ is the dissociation length. For all other cases, we use the repulsive $\varepsilon_{2}$ function.

$$
\begin{gathered}
\varepsilon_{1}(r)=\sum_{k=0}^{4} a_{k}\left(\frac{r_{i j}}{r_{0}}\right)^{k-n} \quad r_{i j} \leq r_{d} \\
\varepsilon_{2}(r)=\frac{\alpha}{\left(\frac{r_{i j}}{r_{0}}\right)^{\gamma}}+\beta, \quad r_{i j} \leq r_{d} \\
\varepsilon_{2}\left(r_{i j}\right)=\varepsilon_{1}\left(r_{i j}\right), \quad r_{i j} \geq r_{d}
\end{gathered}
$$

Parameters ak, $\alpha, \beta$ and $\gamma$ are calculated with the following conditions :

$\varepsilon_{1}\left(\mathrm{r}_{\mathrm{eq}}\right)=\varepsilon_{0}, \varepsilon_{1}{ }^{\prime}\left(\mathrm{r}_{\mathrm{eq}}\right)=0, \varepsilon_{1}\left(\mathrm{r}_{\mathrm{act}}\right)=\mathrm{e}_{\mathrm{act}}, \varepsilon_{1}\left(\mathrm{r}_{\mathrm{act}}\right)=0, \varepsilon_{1}\left(\mathrm{r}_{\mathrm{d}}\right)=0, \varepsilon_{2}\left(\mathrm{r}_{\mathrm{d}}\right)=\varepsilon_{1}\left(\mathrm{r}_{\mathrm{d}}\right)$, $\varepsilon_{2}^{\prime}\left(r_{d}\right)=\varepsilon_{1}^{\prime}\left(r_{d}\right), \varepsilon_{2}^{\prime \prime}\left(r_{d}\right)=\varepsilon_{1}^{\prime \prime}\left(r_{d}\right)$. $r_{e q}$ is equilibrium distance of the $A_{2}$ molecule, $r_{a c t}$ is the position of activation barrier. The parameters used in this work

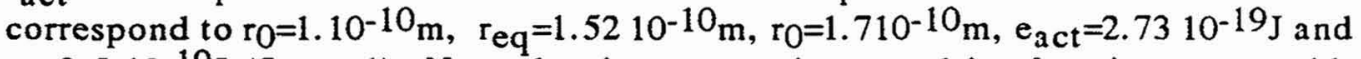
$\varepsilon_{0}=2.510^{-19} \mathrm{~J}$ (figure 1 ). Note that because $\varepsilon_{2}$ is a repulsive function, any stable intermolecular regular structure exists at thermal equilibrium.

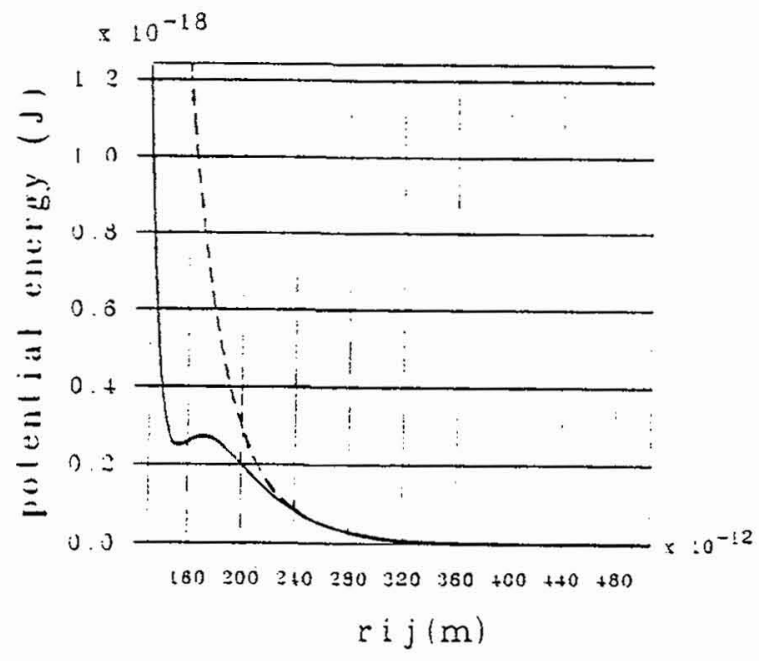

Fig. 1. Potential functions $\varepsilon_{1}(-)$ and $\varepsilon_{2}(--)$ used in this work. 


\section{III - THERMAL DECOMPOSITION.}

The overall system is composed of $8 \times 8 \times 8$ centred cubic unit cells (2048 atoms) with periodic boundaries on each face. Initial velocities are inferred from a Maxwell-Boltzmann distribution corresponding to a $T_{i}$ temperature. Then, the evolution of the system is free and calculations are performed until all $\mathrm{A}_{2}$ molecules are broken. Decomposition fractions are illustrated on figure 2 for five temperatures $\mathrm{T}_{\mathbf{i}}$.

Comparison between the numerical particle velocity distribution and Maxwell Boltzmann distribution calculated from average kinetic energy shows that thermodynamic equilibrium exists at any time; thus thermodynamic parameters are calculated with the usual statistical physics formulation. For example, temperature evolution is shown on figure 3 .

Decomposition fraction versus time can be explained with the molecular collision theory. In this topic, two limit cases exist :

- for high temperatures, the decomposition mechanism is of first order : $A_{2} \rightarrow 2 \mathrm{~A}$.

- for lower temperatures, the decomposition mechanism is of second order :

$2 \mathrm{~A}_{2} \rightarrow 2 \mathrm{~A}+\mathrm{A}_{2}$ or $\mathrm{A}_{2}+\mathrm{A} \rightarrow 3 \mathrm{~A}$.

The Arrhénius constant $\mathrm{k}$ is given by :

$$
k(T(t))=z \sqrt{T(t)} \exp \left(-\frac{e_{a c t}^{\prime}}{k_{b} T(t)}\right)
$$

where $e^{\prime}$ act is an activation energy, $z$ the frequency factor, $T$ the temperature and $\mathrm{k}_{b}$ the Boltzmann's constant (noting that $\mathrm{T}$ is a function of time $t$ ). Numerical resolution of differential equations corresponding to different mechanisms shows that decomposition is of first order for the two higher initial temperatures $(2121 \mathrm{~K}$ and $1806 \mathrm{~K})$, and second order for the lower temperature (1023K). In the intermediate case, beginning of decomposition is of second order and of first order at the end of reaction. Calculated values of $e^{\prime}$ act and $z$ (table 1) are pratically identical for all $\mathrm{T}_{\mathrm{i}}$; this result confirms the choice of theoretical model to describe the numerical results on thermal decomposition. 
Table 1. Kinetic parameters deduced from numerical calculations and molecular theory collision.

\begin{tabular}{|c|c|c|}
\hline$T_{i}(\mathrm{~K})$ & $e_{a c t}^{\prime}(\mathrm{J})$ & $z\left(\mathrm{~s}^{-1} \mathrm{~K}^{-1 / 2}\right)$ \\
\hline 2121 & $810^{-20}$ & $310^{10}$ \\
\hline 1806 & $810^{-20}$ & $310^{10}$ \\
\hline 1508 & $810^{-20}$ & $2,610^{10}$ \\
\hline 1274 & $7,9810^{-20}$ & $3,510^{10}$ \\
\hline 1023 & $8,7710^{-20}$ & $3,9610^{10}$ \\
\hline
\end{tabular}

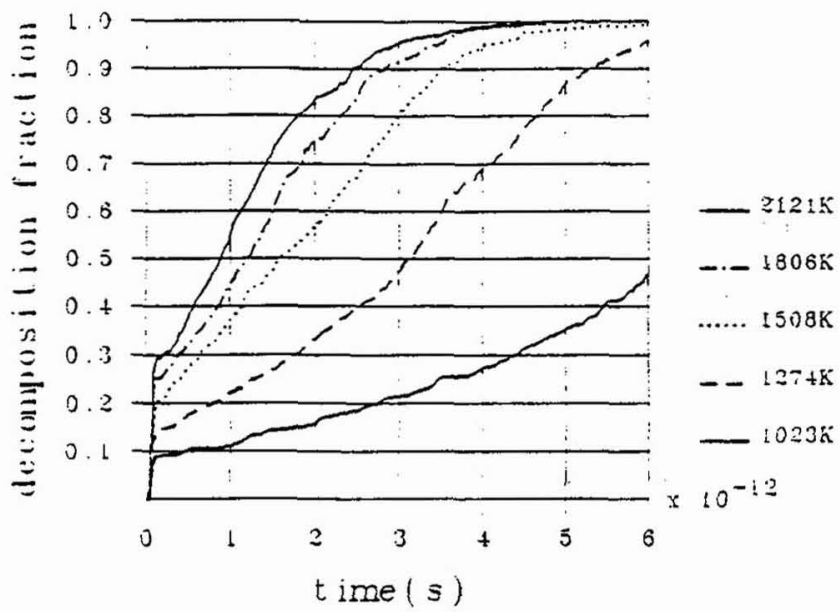

Fig. 2. Decomposition fraction for various initial temperatures. 


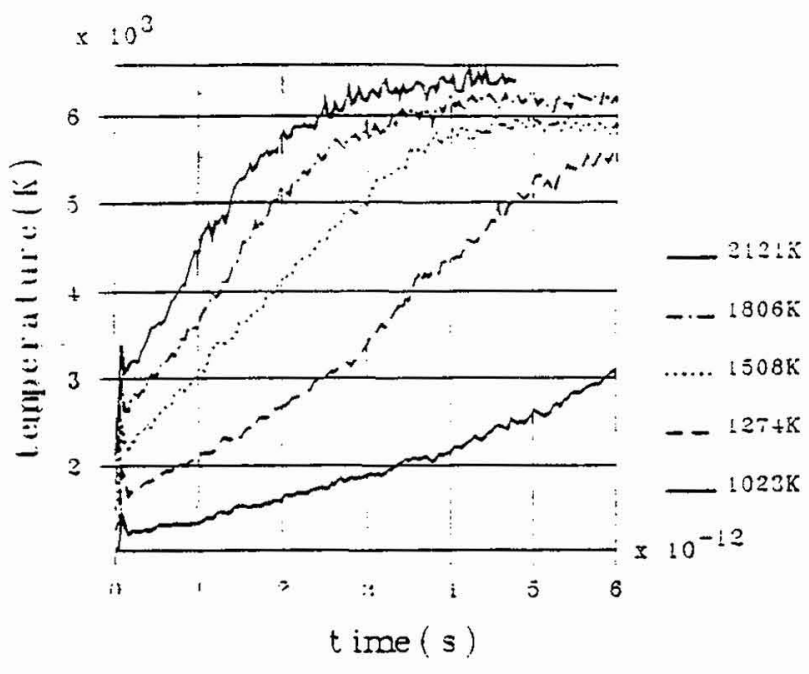

Fig. 3. Temperature of system during decomposition.

\section{IV - SHOCK DECOMPOSITION.}

The system is made up by 60 unit cells in the $x$ direction, and of 3 unit cells in the $y$ and $z$ directions (2160 atomes). The two faces perpendicular to the $x$-axis are mirrors, the other faces are periodic. After thermalisation, all particles move at time $t_{0}$ in the $x$ direction with a velocity $u_{0}$. So, a wave $P$ is generalited in the opposite direction. Three values of $u_{0}$ are used $: 500 \mathrm{~m} / \mathrm{s}, 1500 \mathrm{~m} / \mathrm{s}$ and $2500 \mathrm{~m} / \mathrm{s}$. The initial temperature is $251 \mathrm{~K}$.

For the lower $u_{0}(500 \mathrm{~m} / \mathrm{s})$, any decomposition is observed during the calculation. The wave velocity is constant $(1463 \mathrm{~m} / \mathrm{s})$. For $u_{0}=2500 \mathrm{~m} / \mathrm{s}$, decomposition occurs just on the compression front (figure 4). The wave velocity is constant $(5115 \mathrm{~m} / \mathrm{s})$. The last case $\left(u_{0}=1500 \mathrm{~m} / \mathrm{s}\right)$ is more complicated. We observe two regimes : the first one, between $\mathrm{t}_{0}$ and $4 \cdot 10^{-12} \mathrm{~s}$, corresponds to a wave velocity of $3097 \mathrm{~m} / \mathrm{s}$. Reaction of decomposition occurs behind the compressive zone (figure 5). The wave $P$ is thus an inert wave followed by a reactive wave. In the second regime, between $610^{-12}$ s and the end of calculation, the compression zone is overtaken by 
reaction zone and, as in the $u_{0}=2500 \mathrm{~m} / \mathrm{s}$ case, decomposition occurs on the compression front (figure 6). The wave velocity is $4479 \mathrm{~m} / \mathrm{s}$.

Behind the wave $P$, the thermodynamic equilibrium is rapidly achieved. Comparison between thermodynamic state behind $P$ deduced from the wave velocity, the particle velocity and Hugoniot

relations and thermodynamic state deduced from statistical physics shows that $\mathrm{P}$ is a steady shock wave for $u_{0}=500 \mathrm{~m} / \mathrm{s}$ and $u_{0}=2500 \mathrm{~m} / \mathrm{s}$ (table 2 and 3 ). Shock wave is inert in the first case, and reactive in the second one. For $u_{0}=1500 \mathrm{~m} / \mathrm{s}$, the wave $P$ is not a steady shock wave, because the reaction zone is (relatively) large and unstable in time.

Table 2. Average values for pressure $P$, density $\rho$, internal energy $e$ and temperature $T$ behind shock front deduced from statistical physics analysis.

\begin{tabular}{|c|c|c|c|c|}
\hline$u_{0}(\mathrm{~m} / \mathrm{s})$ & $\langle P>(\mathrm{Pa})$ & $\langle\rho\rangle\left(\mathrm{kg} / \mathrm{m}^{3}\right)$ & $\langle e\rangle(\mathrm{J} / \mathrm{kg})$ & $\langle T\rangle(\mathrm{K})$ \\
\hline 500 & $8,19110^{8}$ & 1275 & $2,79310^{6}$ & 438 \\
\hline 2500 & $1,10110^{10}$ & 1651 & $5,78810^{6}$ & 8669 \\
\hline
\end{tabular}

Table 3. Pressure $P_{O}$ density $\rho_{c}$ and internal energy $e_{c}$ calculated from shock and particle velocities and Hugoniot relations.

\begin{tabular}{|c|c|c|c|}
\hline$u_{0}(\mathrm{~m} / \mathrm{s})$ & $P_{c}(\mathrm{~Pa})$ & $\rho_{C}\left(\mathrm{~kg} / \mathrm{m}^{3}\right)$ & $e_{c}(\mathrm{~J} / \mathrm{kg})$ \\
\hline 500 & $7,7810^{8}$ & 1305 & $2,80010^{6}$ \\
\hline 2500 & $1,11310^{10}$ & 1680 & $5,82410^{6}$ \\
\hline
\end{tabular}

The decomposition under shock is a first order mechanism described in part III of this paper, because temperature behind the shock front is high. Kinetic parameters are not the same for the two cases (table 4). Increasing of $e^{\prime}$ act is probably due to the growth of density with $u_{0}$. Similarly, $z$ must theoretically increase with temperature and density, and thus with $u_{0}$.

Table 4. Kinetic parameters for shock decomposition.

\begin{tabular}{|c|c|c|}
\hline $\mathrm{u}_{0}(\mathrm{~m} / \mathrm{s})$ & $e_{a c t}^{\prime}(\mathrm{J})$ & $\mathrm{z}^{\prime}\left(\mathrm{s}^{-1} \mathrm{~K}^{-1 / 2}\right)$ \\
\hline $1500 \mathrm{~m} / \mathrm{s}$ & $1,7810^{-19}$ & $1,910^{11}$ \\
\hline $2500 \mathrm{~m} / \mathrm{s}$ & $1,8510^{-18}$ & $1,710^{17}$ \\
\hline
\end{tabular}




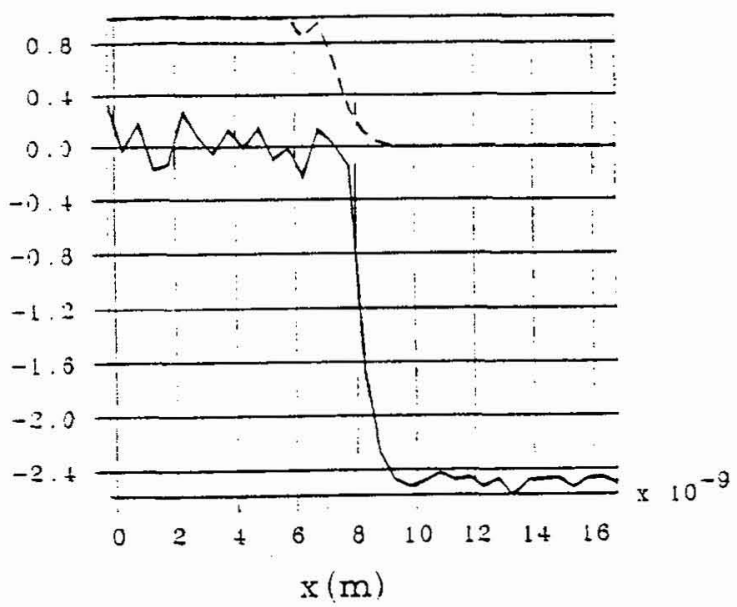

Fig. 4. Average x component particle velocity (-) and fraction decomposition (---) for $u_{0}=2500 \mathrm{~m} / \mathrm{s}$ and $\mathrm{t}=4.43010^{-12} \mathrm{~s}$. Velocities are divided by 1000 .

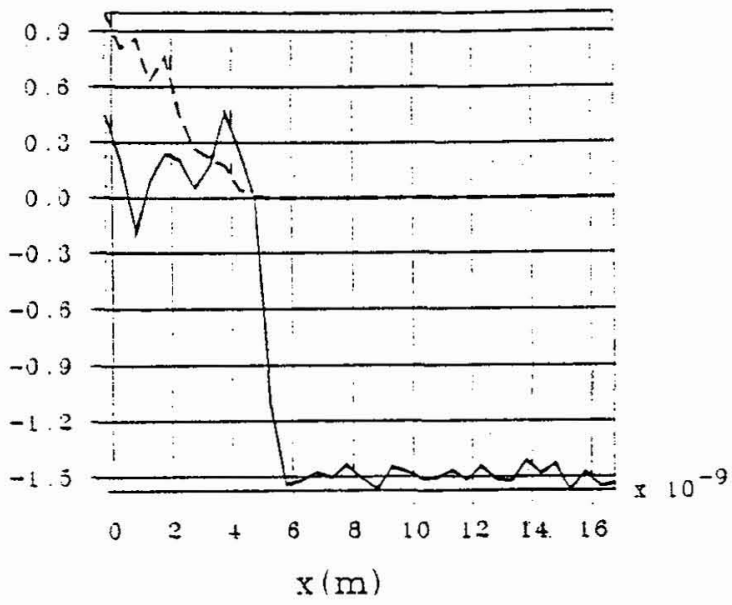

Fig. 5. Average x component particle velocity (-) and fraction decomposition (---) for $u_{0}=1500 \mathrm{~m} / \mathrm{s}$ and $\mathrm{t}=4.43010^{-12} \mathrm{~s}$. Velocities are divided by 1000 . 


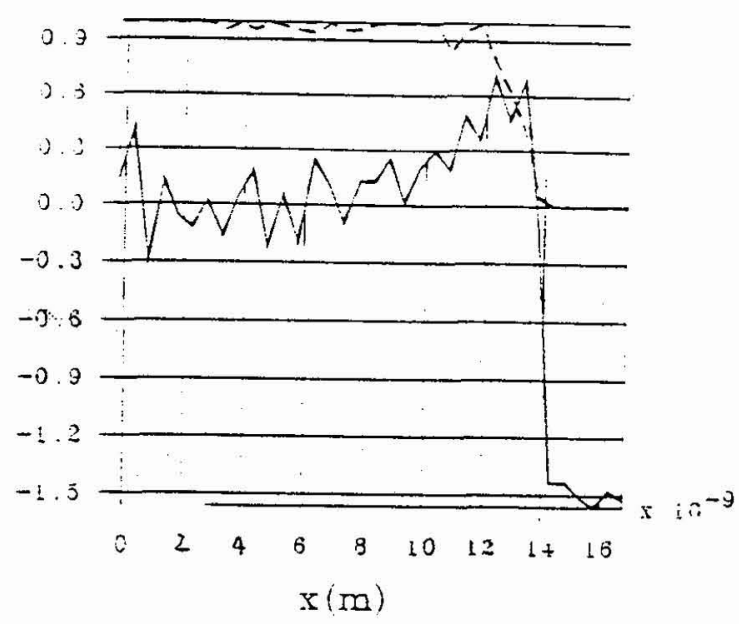

Fig. 6. Average x component particle velocity (-) and fraction decomposition (---) for $\mathrm{u}_{0}=1500 \mathrm{~m} / \mathrm{s}$ and $\mathrm{t}=7.83310^{-12} \mathrm{~s}$. Velocities a re divided by 1000 .

\section{V - DISCUSSION.}

Two main results of this work concern firstly the structure of the reactive shock wave, and secondly the decomposition kinetic under static and dynamic sollicitations. In homogeneous explosives shocked by a projectile, it is currently admitted that decomposition reactions begin at interface explosive/projectile with a significative delay. The reaction zone overtakes the inert shock wave propagating in explosive at rest. Thus, during a short time, the system is composed of explosive at rest, explosive shocked but not decomposed and a reaction zone behind the inert shock front. This structure is the same as the one observed in our molecular dyna mics calculations.

Second point concerns the kinetic parameters for static and dynamic decompositions. Experimental works on PETN single crystal and liquid nitromethane /7-9/ (that are homogeneous explosives) exhibit a strong decay of $z$ and $e_{\text {act }}$ for shock decomposition versus thermal decomposition. Morever, theoretical calculations show that activation energy of nitrogen monoxyde is significantly lowered by intermolecular interaction. Our calculations do not reproduce these results because the potential function used here is too simple. Effect of molecular surrounding on energy activation cannot be taken into account with only a two particles pontential function. Implementation in our code of more realistic potential functions is thus our first aim. 


\section{REFERENCES}

1. Tai-Guang Wei and Robert E. Wyatt, J. Phys. : Condens. Matter, 2, 9787 (1990).

2. Arnold M. Karo and John R. Hardy, International Journal of Quantum Chemistry, XII, 333 (1977).

3. F. E. Walker, A. M. Karo and J. R. Hardy, The Seventh Symposium (International) on Detonation, 716 (1981).

4. D. H. Robertson, D.W.Brenner and C.T.White, Phys; Rev. Lett., 67(2), 3132 (1991).

5. V. Yu Klimenko and A. N. Dremin, Sov. Phys. Dokl., 25(4), 288 (1980).

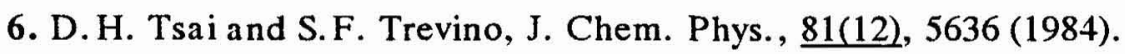

7. A. J.B. Robertson, J. Soc. Chem. Ind., 67, 221 (1948).

8. J.J. Dick, Shock Waves in Condensed Matter, 545 (1985). NSRDS-NBS21 (U.S. Government Printing Office, Wash., D.C., 1970).

9. R. D. Bardo, The Seventh Symposium (International) on Detonation, 93 (1981). 